RESEARCH ARTICLE

\title{
Impact of Spodoptera litura Attack on Chlorophyll and Biomass Content of Vigna mungo Colonized with Arbuscular Mycorrhizal Fungi and Rhizobium
}

\author{
Anandakumar S, Kalaiselvi T* and Sivakumar Uthandi \\ *Department of Agricultural Microbiology, Tamil Nadu Agricultural University, Coimbatore-641 003
}

\begin{abstract}
The first and foremost response of plants to any external stimuli, including herbivorous insect attack is the generation of reactive oxygen species, which majorly occurs in the chloroplast followed by mitochondria, peroxisomes, cell membrane, and cell wall. Under these circumstances, the photosynthetic efficiency of the plant system dramatically influences the plant biomass and yield. Although arbuscular mycorrhizal fungi (AMF), Glomus intraradices and Rhizobium improve plant growth through nutritional modes, their impact on protecting chloroplast from herbivore-induced damage is not yet explored. In this regard, experiments were carried out to examine the changes in

Received : $16^{\text {th }}$ January, 2020

Revised : $12^{\text {th }}$ February, 2020

Accepted : $05^{\text {th }}$ March, 2020

chlorophyll composition (Chl a \& b), and biomass production of Rhizobium brand AMF inoculated plants infested with Spodoptera litura. Among various treatments, AMF and Rhizobium inoculated plants showed higher chlorophyll $a$ and $b$ than un-inoculated control. Upon the herbivore attack, there was a drastic reduction in the chlorophyll content $(a \& b)$ in all the treatments. However, the reduction in chlorophyll content upon S. litura attack was lesser in plants inoculated either with AMF or in the combination of AMF and Rhizobium. Similarly, these microbial inoculants protected the plants from S. litura damage by sustaining the biomass productivity. These results highlight the synergistic effects of AMF and Rhizobium in protecting the black gram plants from herbivore-induced damage.
\end{abstract}

Keywords: Arbuscular mycorrhizal fungi, Glomus intraradices, Rhizobium, Spodoptera litura, chlorophyll, plant biomass

\section{INTRODUCTION}

Vigna mungo, a widely cultivated leguminous crop in India, forms a symbiotic association with Rhizobium and arbuscular mycorrhizal fungi (AMF). Rhizobium is a symbiotic diazotrophic bacterium that fulfills the nitrogen requirement of the plant by fixing atmospheric nitrogen. AMF increases plant growth by facilitating the absorption of immobile nutrients (phosphate, ammonium \& micronutrients) and moisture through its extensive external hyphal network. These two beneficial microbes improve plant growth by increasing nutrient availability and modulating the physiological characteristics of the plants (Laouane et al., 2019). Improved growth in mycorrhiza associated plants due to higher photosynthetic activity was reported (Kumar et al., 2019). Earlier reports indicate that there is an increase in leaf area and chlorophyll content of mycorrhizae treated plants due to higher phosphorus availability (Dietz and Foyer, 1986; Xu et al., 2018). Non-mycorrhizal plants contained lesser chlorophyll than those of mycorrhizal plants (Giri et al., 2003). Glomus etunicatum (AMF) inoculated pistachio (Pistacia vera L.) seedlings recorded higher chlorophyll over non-mycorrhizal pistachio plants (Abbaspour et al., 2012). Mycorrhizal plants had significantly higher chlorophyll, dry, and fresh biomass than plants are grown in sterilized soil (Zare-Maivan et al., 2017).

Spodoptera litura is a polyphagous leaf-feeding insect responsible for a significant reduction in yield of black gram (Sreelakshmi et al., 2019). Herbivorous insects induce biochemical and physiological changes in the host plants, affecting critical vital processes such as photosynthesis (Goławska et al., 2010). It occurs in plants exposed to stress due to photo-oxidation of chlorophyll by the toxic oxygen species. In response to it, some plants develop photo-protective mechanisms to counteract the ill effects of toxic oxygen species through enzymatic and non-enzymatic modes. The decrease in chlorophyll content in response to a variety of stresses including insect feeding (Goławska et al., 2010; Heng-Moss et al., 2003; Ni et al., 2002; Ni 
et al., 2001; Santamaría et al., 2018) has been reported earlier. Thus, chlorophyll content could be an indicator of investigating plants' resistance to various stresses.

The plethora of earlier reports indicates that AMF improves plant chlorophyll and biomass production under abiotic stress conditions (Bagheri et al., 2019; Goławska et al., 2010; Huang et al., 2014). Studies are imperative to address the effect of $S$. litura attack on the physiological properties of the plant viz., chlorophyll, and biomass productivity. Thus, studies were undertaken to investigate the effect of AMF and Rhizobium in protecting plants chlorophyll from biotic stress (Spodoptera litura).

\section{MATERIAL AND METHODS}

\section{Microbial cultures}

Glomus intraradices spores were obtained from the Department of Agricultural Microbiology, Tamil Nadu Agricultural University, Coimbatore. AM fungal spores were mass multiplied in sand using maize and used as a source of inoculum. Rhizobium BMBS strain was obtained from the Department of Agricultural Microbiology, Tamil Nadu Agricultural University, Coimbatore. It was multiplied in yeast extract mannitol (YEM) broth by incubating at $28{ }^{\circ} \mathrm{C}$ for 2 days in an Orbital shaker with $150 \mathrm{rpm}$. Then, the broth was centrifuged at $10000 \mathrm{rpm}$ for $10 \mathrm{~min}$ under the refrigerated condition, and the cell pellet was collected. The cell pellet was then suspended in $1 \mathrm{~mL}$ of sterile distilled water and used as a source of inoculum.

\section{Plant growth and microbial inoculation}

Vigna mungo (CO 6) seeds used for this study were obtained from the Department of Pulses, Tamil Nadu Agricultural University, Coimbatore. Surface sterilized seeds (10\% sodium hypochlorite for $5 \mathrm{~min}$ followed by $70 \%$ ethanol for $3 \mathrm{~min}$. and then with sterile water 3- 4 times) inoculated with Glomus intraradices and Rhizobium were dibbled in $2 \mathrm{~kg}$ capacity pot containing a mixture of sterile red soil and sand at the ratio of 2:1. After seed germination, all the pots were irrigated alternatively with $100 \mathrm{~mL}$ Hoagland nutrient solution and $100 \mathrm{~mL}$ tap water at two days interval.

\section{Insect treatment}

Spodoptera litura egg mass was purchased from the National Bureau of Agricultural Insect Resources, Bengaluru. Insect eggs were kept in a plastic container with castor leaves until they reach the stage of third instar larvae and used as a source of insect material. After 40 days of sowing, plants were subjected to insect damage by releasing three number of third instar Spodoptera litura larvae. This investigation was carried out with eight treatments and three replications following a completely randomized design. The treatments include (C) without microbial inoculants and S. litura; (S) S. litura; $(\mathrm{R})$ Rhizobium; $(\mathrm{R} * \mathrm{~S})$ Rhizobium and S. litura; (G) Glomus intraradices; (G*S) G. intraradices and S. litura; $(G * R)$ G. intraradices and Rhizobium; and $(G * R * S) G$. intraradices, Rhizobium and S. litura. The total number of 24 pots with three replications per treatment and one-pot per replication was maintained. Plants were uprooted after 12, 24 , 48 and 96 h of S. litura treatment and used for assessing the chlorophyll content, plant biomass, mycorrhizal colonization, and root nodulation

\section{Leaf chlorophyll}

Chlorophyll was estimated based on the procedure of Arnon (1949) for which about 100 $\mathrm{mg}$ of fresh leaf tissue was macerated in $5 \mathrm{~mL}$ of $80 \%$ acetone and then centrifuged for $10 \mathrm{~min}$ at 3000 rpm under refrigerated condition. This step was repeated until all the chlorophyll was extracted. Then, the extracts were pooled and the volume was made up to $10 \mathrm{ml}$ with $80 \%$ acetone. The intensity of green color was measured at 480 and $510 \mathrm{~nm}$ in a digital spectrophotometer (Spectramax ${ }^{\circledR}$ i3X) for chlorophyll a and chlorophyll b, respectively. Acetone (80 \%) was used as a blank. The chlorophyll content was denoted as $\mathrm{mg} \mathrm{g}^{-1}$ fresh leaf material.

\section{Total biomass}

Plants were harvested after 12, 24, 48, and $96 \mathrm{~h}$ of insect release and oven-dried at $70^{\circ} \mathrm{C}$ for $4 \mathrm{~h}$. The dry weight of shoot and root system was recorded and expressed as g plant ${ }^{-1}$.

\section{Nodulation and AM fungi colonization}

Mycorrhizal colonization and nodulation were assessed at the end of the experiment. Plants were uprooted and washed gently with running tap water. First, nodules were counted and expressed as a number of nodules plant ${ }^{-1}$. For mycorrhizal colonization, the roots were cut into small bits, treated with $10 \% \mathrm{KOH}$ solution, and autoclaved. Then, the root bits were treated with $2 \% \mathrm{HCl}$ solution after decanting the alkali. After acid treatment, the roots were stained with $0.008 \%$ trypan blue for 24 $\mathrm{h}$ and then observed under a low power compound microscope. The mycorrhizal colonization was expressed in percentage (Phillips and Hayman, 1970).

\section{Statistical analysis}

Statistical analysis was done using the software, SPSS (Version 16.0), and Microsoft Excel. Values of mycorrhizal colonization and nodule number were transformed into arcsine $(x / 100)$ and $\log (x+1)$, respectively. One way analysis of variance (One way ANOVA) was done for the data concerned with 
mycorrhizal colonization, and nodulation efficiency and the results were stated as mean with standard error (mean $\pm \mathrm{SE}$ ). Duncan's multiple range test (DMRT) was performed at $P<0.05$ to compare the mean values. Three way analysis of variance (three-way ANOVA) was done to study the interaction effects of G. intraradices, Rhizobium, and the timing of insect release on the changes in chlorophyll $a, b$ and total biomass production.

\section{RESULTS AND DISCUSSION}

The chlorophyll and biomass content of 40 days old black gram plants were measured at four different time intervals (12, 24, 48 and 96 h ) after insect release in eight different treatments. As expected, the chlorophyll content was higher in inoculated plants over un-inoculated control. However, S. litura infestation reduced chlorophyll content and plant biomass production in all the treatments. However, the reduction in chlorophyll and biomass content was lesser when S. litura attacked AMF and Rhizobium inoculated plants.

\section{Changes in chlorophyll content of AMF and Rhizobium inoculated black gram infested with S. litura}

The concentration of chlorophyll-a of plants inoculated with AMF and Rhizobium (1.30 $\mathrm{mg} \mathrm{g}^{-1} \mathrm{FW}$ after $12 \mathrm{~h}$ ) was almost doubled the concentration of control plants $\left(0.63 \mathrm{mg} \mathrm{g}^{-1} \mathrm{FW}\right.$ after $\left.12 \mathrm{~h}\right)$ in all the time intervals. The chlorophyll content increased due to Rhizobium, AMF, and dual inoculation with AMF and Rhizobium in all time intervals (Figure 1). The chlorophyll a content of plants did not reduce significantly when samples were analyzed after 12 h of herbivory $(P=0.001)$. However, the chlorophyll a content of plants of all the treatments reduced significantly from 24 of insect release to $96 \mathrm{~h}$ (Figure 1 \& Table 1).

Table 1. Effect of Glomus intraradices, Rhizobium and Spodoptera litura on modulating chlorophyll a and b content of blackgram

\begin{tabular}{|c|c|c|c|c|c|}
\hline \multirow{2}{*}{ Treatments } & \multicolumn{3}{|c|}{ Chl a } & \multicolumn{2}{|c|}{ Chl b } \\
\hline & $D f$ & $F$ & $P$ & $F$ & $P$ \\
\hline $\mathrm{G}$ & 1 & 1636.0 & 0.001 & 1025.0 & 0.001 \\
\hline $\mathrm{R}$ & 1 & 245.87 & 0.001 & 181.24 & 0.001 \\
\hline S & 1 & 259.73 & 0.001 & 38.033 & 0.001 \\
\hline $\mathrm{T}$ & 3 & 57.190 & 0.001 & 2.904 & 0.041 \\
\hline$G * R$ & 1 & 82.380 & 0.001 & 17.395 & 0.001 \\
\hline $\mathrm{G} * \mathrm{~S}$ & 1 & 4.0290 & 0.049 & 2.886 & 0.094 \\
\hline $\mathrm{G} * \mathrm{~T}$ & 3 & 5.810 & 0.001 & 0.853 & 0.470 \\
\hline $\mathrm{R} * \mathrm{~S}$ & 1 & 0.001 & 0.978 & 12.409 & 0.001 \\
\hline $\mathrm{R} * \mathrm{~T}$ & 3 & 2.220 & 0.094 & 3.262 & 0.027 \\
\hline $\mathrm{S} * \mathrm{~T}$ & 3 & 33.420 & 0.001 & 4.741 & 0.005 \\
\hline $\mathrm{G} * \mathrm{R} * \mathrm{~S}$ & 1 & 0.554 & 0.460 & 11.485 & 0.001 \\
\hline $\mathrm{G} * \mathrm{R} * \mathrm{~T}$ & 3 & 2.084 & 0.111 & 0.093 & 0.964 \\
\hline $\mathrm{G} * \mathrm{~S} * \mathrm{~T}$ & 3 & 2.666 & 0.055 & 6.869 & 0.001 \\
\hline $\mathrm{R} * \mathrm{~S} * \mathrm{~T}$ & 3 & 0.231 & 0.875 & 0.839 & 0.477 \\
\hline $\mathrm{G} * \mathrm{R} * \mathrm{~S} * \mathrm{~T}$ & 3 & 0.001 & 0.952 & 3.966 & 0.012 \\
\hline Error & & & & & 64 \\
\hline
\end{tabular}

The P-values indicate statistical significance $(p<.05)$. C, Control; G, G. intraradices; R, Rhizobium; S, S. litura; T, Time.

In the absence of herbivory, both AMF and Rhizobium colonized plants recorded a higher concentration of chlorophyll a of $1.33 \mathrm{mg} \mathrm{g}^{-1} \mathrm{FW}$ (24 h); while uninoculated control plants recorded minimum value of $0.30 \mathrm{mg} \mathrm{g}^{-1} \mathrm{FW}$ after $96 \mathrm{~h}$ of insect attack (Table 1).

Similar to chlorophyll a, chlorophyll b content was higher in plants inoculated with both AMF and Rhizobium (1.34 $\mathrm{mg} \mathrm{g}^{-1} \mathrm{FW}$ ). Uninoculated control plants exposed to $S$. litura recorded a minimum value of $01.6 \mathrm{mg} \mathrm{g}^{-1} \mathrm{FW}$ after $96 \mathrm{~h}$ of herbivory (Figure 2). Even though microbial inoculants significantly improved the chlorophyll b content as that of chlorophyll a, herbivory treatment on uninoculated control, single inoculation with AMF and Rhizobium did not alter the chlorophyll content significantly
$(P=0.001$; Table 1). These plants registered almost similar concentrations of chlorophyll $b$ in both insect attacked and normal plants till $48 \mathrm{~h}$. A significant reduction in chlorophyll $\mathrm{b}$ content due to herbivory was observed only after $96 \mathrm{~h}$ of insect release in these treatments. However, S. litura attack on AMF and Rhizobium co-inoculated plants significantly reduced the chlorophyll content after $12 \mathrm{~h}$ of insect release itself. Compared to chlorophyll b, chlorophyll a was significantly influenced by various microbial treatments (Table 1 \& Figure 2). However, AMF and Rhizobium inoculated plants showed a similar trend for chlorophyll $a$ and $b$ both in the presence and absence of insects. Similar to our study, Porra (2002) used leaf chlorophyll content as an indicator of plant health. The chlorophyll a: b ratio also specifies the 
developmental state of photosynthetic apparatus in plants. Many reports indicated chlorophyll content and photosynthetic activity of plant tissue as primary physiological indicators of interactions between plants and herbivores (Goławska et al., 2010; Golan et al., 2015; Mohammed et al., 2019).

Table 2. Effect of Glomus intraradices, Rhizobium and Spodoptera litura on plant biomass production of blackgram

\begin{tabular}{|c|c|c|c|}
\hline \multirow{2}{*}{ Treatments } & \multicolumn{3}{|c|}{ Plant biomass } \\
\hline & $D f$ & $F$ & $P$ \\
\hline $\mathrm{G}$ & 1 & 1386.0 & 0.001 \\
\hline $\mathrm{R}$ & 1 & 450.049 & 0.001 \\
\hline $\mathrm{S}$ & 1 & 123.740 & 0.001 \\
\hline $\mathrm{T}$ & 3 & 17.494 & 0.001 \\
\hline $\mathrm{G} * \mathrm{R}$ & 1 & 294.042 & 0.001 \\
\hline $\mathrm{G} * \mathrm{~S}$ & 1 & 0.012 & 0.914 \\
\hline $\mathrm{G} * \mathrm{~T}$ & 3 & 1.354 & 0.265 \\
\hline $\mathrm{R} * \mathrm{~S}$ & 1 & 14.411 & 0.001 \\
\hline $\mathrm{R} * \mathrm{~T}$ & 3 & 0.928 & 0.432 \\
\hline $\mathrm{S} * \mathrm{~T}$ & 3 & 27.973 & 0.001 \\
\hline $\mathrm{G} * \mathrm{R} * \mathrm{~S}$ & 1 & 0.277 & 0.601 \\
\hline $\mathrm{G} * \mathrm{R} * \mathrm{~T}$ & 3 & 0.847 & 0.473 \\
\hline $\mathrm{G} * \mathrm{~S} * \mathrm{~T}$ & 3 & 0.088 & 0.967 \\
\hline $\mathrm{R} * \mathrm{~S} * \mathrm{~T}$ & 3 & 1.508 & 0.221 \\
\hline $\mathrm{G} * \mathrm{R} * \mathrm{~S} * \mathrm{~T}$ & 3 & 4.803 & 0.004 \\
\hline Error & & & 64 \\
\hline
\end{tabular}

The chlorophyll content of Bougainvillea was higher in control plants than mealybugs infected plants, indicating that insect attack severely compromised the photosynthetic activity of infected plants (Abbate et al., 2018). Losses in chlorophyll content of leaves of Vitis vinifera $L$ have been reported in response to feeding by frosted scale,
Parthenolecanium pruinosum (Simbiken et al., 2015). Many reports have revealed that herbivore feeding affected the chlorophyll content of plants (Ramamurthy et al., 1997; Heng-Moss et al., 2003; $\mathrm{Ni}$ et al., 2002; Mohammed et al., 2019). AM fungal colonization significantly increased the leaf chlorophyll content (Formenti and Rasmann, 2019).

Table 3. Effect of Glomus intraradices infection potential in blackgram

\begin{tabular}{|c|c|c|c|c|c|c|c|c|}
\hline \multirow{2}{*}{ Treatments } & \multicolumn{8}{|c|}{ Mycorrhizal infection (\%) } \\
\hline & \multicolumn{2}{|r|}{$12 \mathrm{~h}$} & \multicolumn{2}{|c|}{$24 \mathrm{~h}$} & \multicolumn{2}{|r|}{$48 \mathrm{~h}$} & \multicolumn{2}{|r|}{$96 h$} \\
\hline $\mathrm{C}$ & & 0.00 & & 0.00 & & 0.00 & & 0.00 \\
\hline $\mathrm{S}$ & & 0.00 & & 0.00 & & 0.00 & & 0.00 \\
\hline $\mathrm{R}$ & & 0.00 & & 0.00 & & 0.00 & & 0.00 \\
\hline $\mathrm{R} * \mathrm{~S}$ & & 0.00 & & 0.00 & & 0.00 & & 0.00 \\
\hline G & 0.99 & $0.06^{b}$ & 1.15 & $0.05^{a}$ & 1.15 & $0.047^{a}$ & 1.12 & $0.07^{a}$ \\
\hline $\mathrm{G} * \mathrm{~S}$ & 1.12 & $0.07^{a}$ & 0.96 & $0.04^{b}$ & 1.12 & $0.07^{a}$ & 1.11 & $0.07^{a}$ \\
\hline $\mathrm{G} * \mathrm{R}$ & 1.08 & $0.11^{\mathrm{b}}$ & 1.15 & $0.04^{a}$ & 1.12 & $0.07^{a}$ & $1 . .20$ & $0.05^{a}$ \\
\hline $\mathrm{F}^{*} \mathrm{R} * \mathrm{~S}$ & 1.07 & $0.04^{b}$ & 1.08 & $0.09^{a}$ & 1.07 & $0.03^{a}$ & 1.15 & $0.04^{a}$ \\
\hline Df & & & & & & & & 7 \\
\hline $\mathrm{F}$ & & 6.724 & & 8.048 & & 91.122 & & 3.157 \\
\hline $\mathrm{P}$ & & 0.000 & & 0.000 & & 0.000 & & 0.000 \\
\hline
\end{tabular}
G. intraradices; R, Rhizobium; S, S. litura.

\section{Changes in plant biomass production of AMF and Rhizobium inoculated blackgram infested with S. litura}

In this study, plants inoculated with AMF produced maximum biomass indicating the importance of AMF in improving plant growth and development. There was no change in biomass production in all the treatments due to herbivory when the biomass was analyzed after $12 \mathrm{~h}$ of insect release (Figure 3 ). In

$107|1-3| 64$ all time intervals, AMF and Rhizobium inoculated plants registered more biomass. AMF + Rhizobium inoculated plants showed maximum biomass productivity (3.49 $\mathrm{g} \mathrm{plant}^{-1}$ ); while uninoculated control plants recorded a minimum of 0.59 g plant $^{-1}$. In general, biomass production reduced only after $24 \mathrm{~h}$ of insect release (Table 2). Overall, biomass production was higher due to AMF and Rhizobium either singly or in combination irrespective of the insect attack. Similarly, Kempel et al. (2010) 
Table 4. Effect of Rhizobium inoculation on root nodulation potential in blackgram

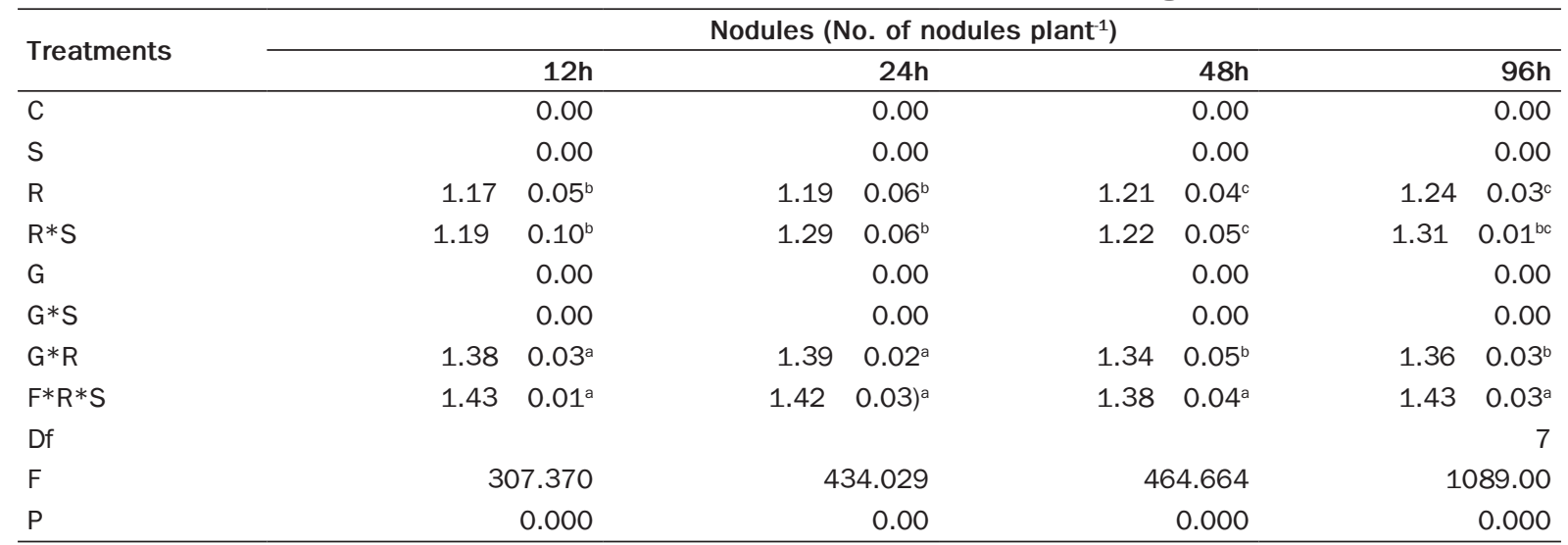

Data in the table are expressed as mean \pm SE. Mean values followed by the same alphabet do not differ significantly at $P \leq 0.05$ by DMRT. C, Control; G, G. intraradices; R, Rhizobium; S, S. litura.

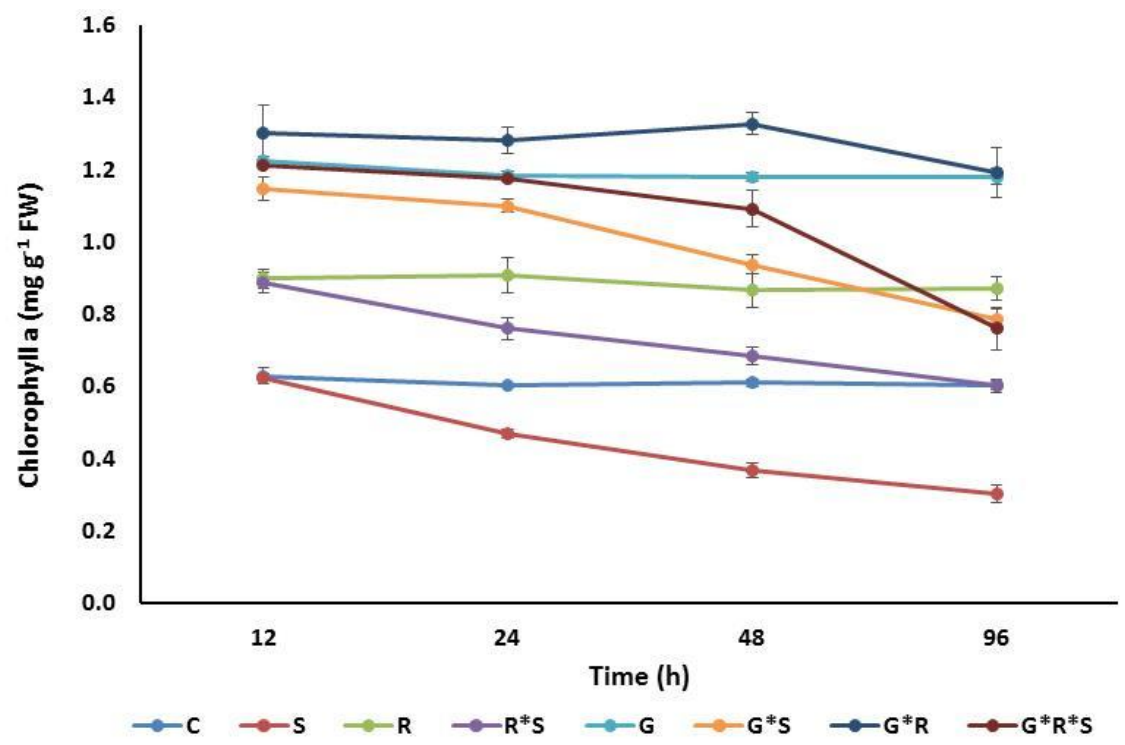

Figure 1. Effect of Glomus intraradices, Rhizobium and Spodoptera litura on modulating chlorophyll a content of blackgram at different time intervals (12, 24, 48 \& 96 h). C, Control; G, G. intraradices; R, Rhizobium; S, S. litura. Data in the figure are expressed as mean $\pm \mathrm{SE}$. Mean values followed by the same letter do not differ significantly at P $\leq 0.05$ by DMRT.

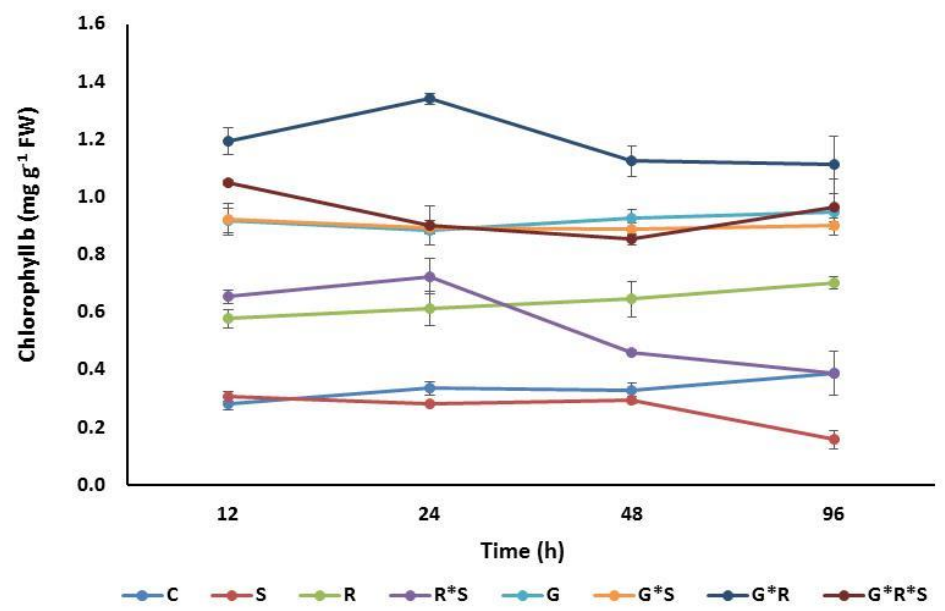

Figure 2. Effect of Glomus intraradices, Rhizobium and Spodoptera litura on modulating chlorophyll b content of blackgram at different time intervals (12, 24, 48 \& 96 h). C, Control; G, G. intraradices; R, Rhizobium; S, S. litura. Data in the figure are expressed as mean \pm SE. Mean values followed by the same letter do not differ significantly at $\mathrm{P} \leq \mathbf{0 . 0 5}$ by DMRT. 
reported an increase in above-ground plant growth of AMF colonized Poa pratensis in the absence of herbivory (Spodoptera littoralis). Similar to our study, Formenti and Rasmann, (2019) reported higher biomass in Solanum lycopersicum due to arbuscular mycorrhizal fungal colonization.

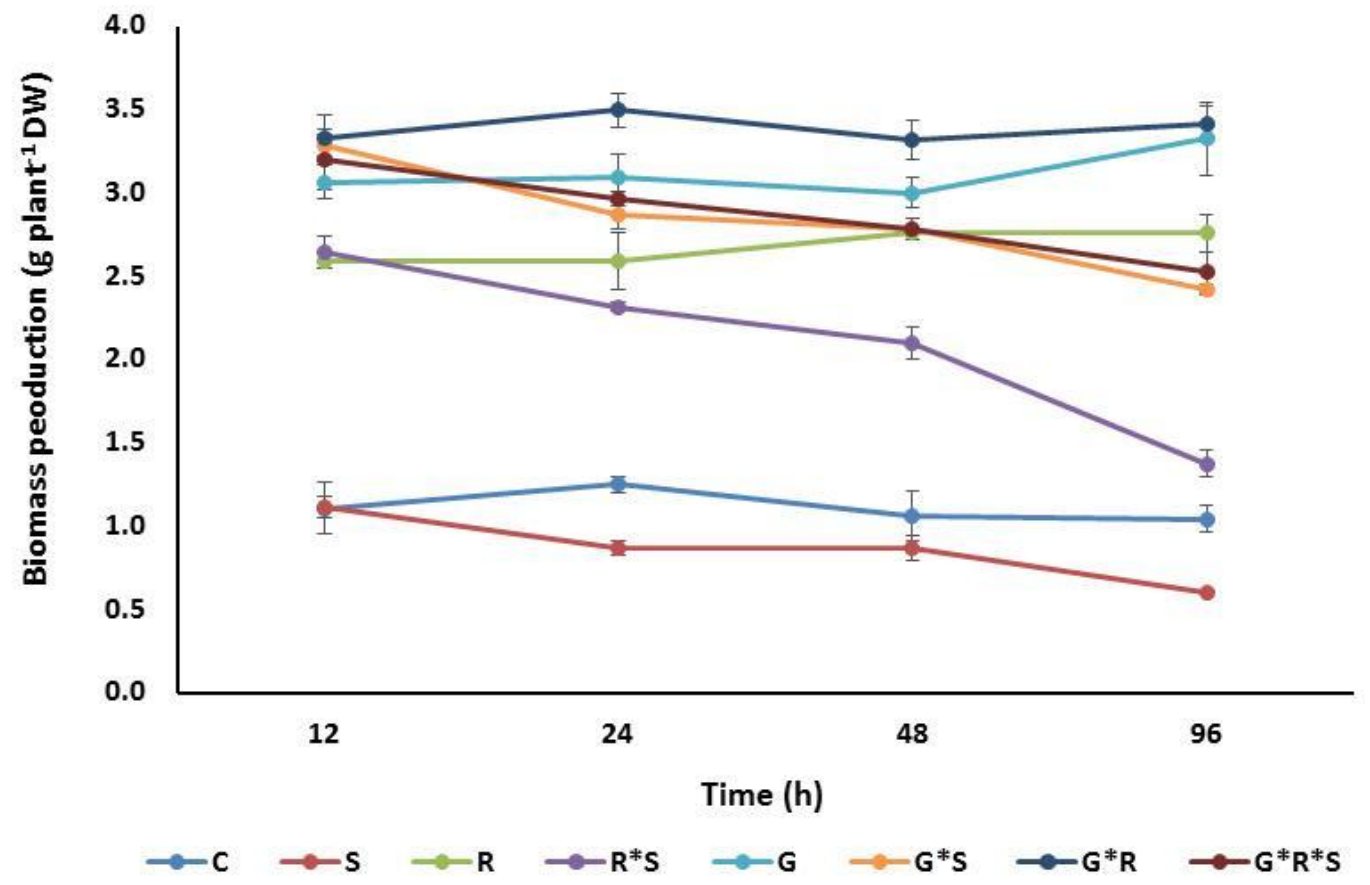

Figure 3. Effect of Glomus intraradices, Rhizobium and Spodoptera litura on modulating plant biomass production of blackgram at different time intervals (12, 24, 48 \& 96 h). C, Control; G, G. intraradices; R, Rhizobium; S, S. litura. Data in the figure are expressed as mean \pm SE. Mean values followed by the same letter do not differ significantly at $\mathrm{P} \leq \mathbf{0 . 0 5}$ by DMRT.

\section{Nodulation and AMF colonization ability of blackgram}

Blackgram plants co-inoculated with AMF and Rhizobium produced more nodules per plant over plants treated with Rhizobium alone (Table 3). Plants treated with AMF and AMF + Rhizobium recorded maximum AMF colonization (Table 4). Thus, the results of the current study indicate that inoculation of blackgram plants microbial symbionts like AMF and Rhizobium could help in reducing the loss of plant biomass due to herbivory. The mechanism of action might be because of improved antioxidants production in AMF and Rhizobium inoculated plants upon herbivory for protecting chlorophyll from herbivore-induced oxygen damage.

\section{CONCLUSION}

The results revealed that chlorophyll and biomass contents of blackgram plants inoculated either singly or jointly with AMF and Rhizobium were greater over uninoculated plants. Upon exposure to S. litura, these plant parameters reduced significantly in all the treatments except the treatments inoculated with AMF. These results indicate that AMF and Rhizobium inoculation could minimize chlorophyll damage and plant biomass production during herbivory. Thus, AMF alone or in combination with Rhizobium could act as a bioprotective agent and be a part of the integrated pest management system.

\section{ACKNOWLEDGEMENT}

The authors are grateful to the Government of India - Ministry of Human Resource Development (GOI-MHRD-FAST) - Microbes to Feed the World (grant F.No. 5-5/2014-TS-VII dt. 04.09.2014) for providing student research fellowship.

\section{REFERENCES}

Abbaspour, H., Saeidi-Sar, S., Afshari, H. and M. AbdelWahhab. (2012). Tolerance of mycorrhiza infected pistachio (Pistacia vera L.) seedling to drought stress under glasshouse conditions. J. Plant Physio., 169 (7): 704-709.

Abbate, C., Toscano, S., Arcidiacono, R., Romano, D., Russo, A. and G. Mazzeo. (2018). Induced responses of Bougainvillea glabra Choisy (Nyctaginaceae) against Phenacoccus peruvianus Granara de Willink (Hemiptera: Pseudococcidae) attack: preliminary results. Arthropod-Plant Interact., 12(1): 41-48.

Arnon, D.I. (1949). Copper enzymes in isolated chloroplasts. Polyphenoloxidase in Beta vulgaris. Plant physiol., 24(1): 1.

Bagheri, V., Shamshiri, M., Alaei, H. and H. Salehi.

$107|1-3| 66$ 
(2019). The role of inoculum identity for growth, photosynthesis, and chlorophyll fluorescence of zinnia plants by arbuscular mycorrhizal fungi under varying water regimes. Photosynthetica., 57(2): 409-419.

Laouane, R. B., Meddich, A., Bechtaoui, N., Oufdou, K. and S. Wahbi. (2019). Effects of arbuscular mycorrhizal fungi and rhizobia symbiosis on the tolerance of Medicago Sativa to Salt Stress. Gesunde Pflanzen. 71(2): 135-146.

Dietz, K. J. and C. Foyer. (1986). The relationship between phosphate status and photosynthesis in leaves: effects on intracellular orthophosphate distribution, photosynthesis and assimilate partitioning. Planta., 167(3): 376-381.

Formenti, L. and S. Rasmann. (2019). Mycorrhizal fungi enhance resistance to herbivores in tomato plants with reduced jasmonic acid production. Agronomy., 9(3): 131

Giri, B., Kapoor, R. and K. Mukerji. (2003). Influence of arbuscular mycorrhizal fungi and salinity on growth, biomass, and mineral nutrition of Acacia auriculiformis. Biol. Fertil. Soils., 38(3): 170-175.

Golan, K., Rubinowska, K., Kmiec, K., Kot, I., GorskaDrabik, E., agowska, B. and W. Micha ek. (2015). Impact of scale insect infestation on the content of photosynthetic pigments and chlorophyll fluorescence in two host plant species. ArthropodPlant Interact., 9(1): 55-65.

Go awska, S., Krzy anowski, R. and I. ukasik. (2010). Relationship between aphid infestation and chlorophyll content in Fabaceae species. Acta Biol. Crac. Ser. Bot., 52(2): 76-80.

Heng-Moss, T., Ni, X., Macedo, T., Markwell, J.P., Baxendale, F.P., Quisenberry, S. and V. Tolmay. (2003). Comparison of chlorophyll and carotenoid concentrations among Russian wheat aphid (Homoptera: Aphididae)-infested wheat isolines. J. Econ. Entomol., 96(2): 475-481.

Huang, T.I., Reed, D.A., Perring, T.M. and J.C. Palumbo. (2014). Feeding damage by Bagrada hilaris (Hemiptera: Pentatomidae) and impact on growth and chlorophyll content of Brassicaceous plant species. Arthropod-Plant Interact., 8(2): 89-100.

Kempel, A., Schmidt, A.K., Brandl, R. and M. Schädler. (2010). Support from the underground: induced plant resistance depends on arbuscular mycorrhizal fungi. Funct. Ecol., 24(2): 293-300.

Kumar, P., Dey, S.R., Komal, J.Y. and A. Siddique. (2019). Effect of polyamines and endo-mycorrhiza on chlorophyll a, b ratio and total carotenoids in leaves of Sorghum grown under cadmium toxicity. Int. J. Chem. Stud., 7(1): 2402-2406.
Mohammed, A.F., Kamel, M.S. and A.K. Mahmoud. (2019). Interlaced influence of arbuscular mycorrhiza and water management on mite infestation and kohlrabi production. Agr. Nat. Resour., 53(3), 205-217.

Ni, X., Quisenberry, S.S., Heng-Moss, T., Markwell, J., Higley, L., Baxendale, F. and R. Klucas. (2002). Dynamic change in photosynthetic pigments and chlorophyll degradation elicited by cereal aphid feeding. Entomol. Exp. Appl., 105(1): 43-53.

Ni, X., Quisenberry, S.S., Markwell, J., Heng-Moss, T., Higley, L., Baxendale, F. and R. Klucas. (2001). In vitro enzymatic chlorophyll catabolism in wheat elicited by cereal aphid feeding. Entomol. Exp. Appl., 101(2): 159-166.

Phillips, J.M. and D. Hayman. (1970). Improved procedures for clearing roots and staining parasitic and vesicular-arbuscular mycorrhizal fungi for rapid assessment of infection. Trans. Br. Mycol. Soc., 55(1): 118-158.

Porra, R.J. (2002). The chequered history of the development and use of simultaneous equations for the accurate determination of chlorophylls $a$ and b. Photosynth. Res., 73(1-3): 149-156.

Ramamurthy, V.V., Kumaraswami, T., and S. Jayaraj. (1977). Effect of whorl maggot damage on the contents of chlorophyll and reduced sugars and uptake of nutrients in rice seedlings. Madras Agric.J., 64(6): 405-406.

Santamaría, M. E., Arnaiz, A., Velasco-Arroyo, B., Grbic, V., Diaz, I. and M. Martinez. (2018). Arabidopsis response to the spider mite Tetranychus urticae depends on the regulation of reactive oxygen species homeostasis. Sci. Rep., 8(1): 9432.

Simbiken, N., Cooper, P. and K. Powell. (2015). Development and feeding effect of frosted scale Parthenolecanium pruinosum Cocquillet (Hemiptera: Coccidae) on selected Vitis vinifera L. cultivars. Aust. J. Grape Wine Res., 21(3): 451-457.

Sreelakshmi, P., Mathew, T.B., Umamaheswaran, K. and A. Josephrajkumar. (2019). Modulation in activity profiles in insecticide-resistant population of tobacco caterpillar, Spodoptera litura(Fabricius). Curr. Sci., 116(4).

Xu, H., Lu, Y. and S. Tong. (2018). Effects of arbuscular mycorrhizal fungi on photosynthesis and chlorophyll fluorescence of maize seedlings under salt stress. Emi. J. Food Agric., 199-204.

Zare-Maivan, H., Khanpour-Ardestani, N. and F. Ghanati. (2017). Influence of mycorrhizal fungi on growth, chlorophyll content, and potassium and magnesium uptake in maize. J. Plant Nutr., 40(14): 2026-2032. 